\title{
Minute Times Picomole Per Liter Per Milligram Per Gram
}

National Cancer Institute

\section{Source}

National Cancer Institute. Minute Times Picomole Per Liter Per Milligram Per Gram. NCI

Thesaurus. Code C117954.

Minute times picomole per liter, divided by milligram per gram. 